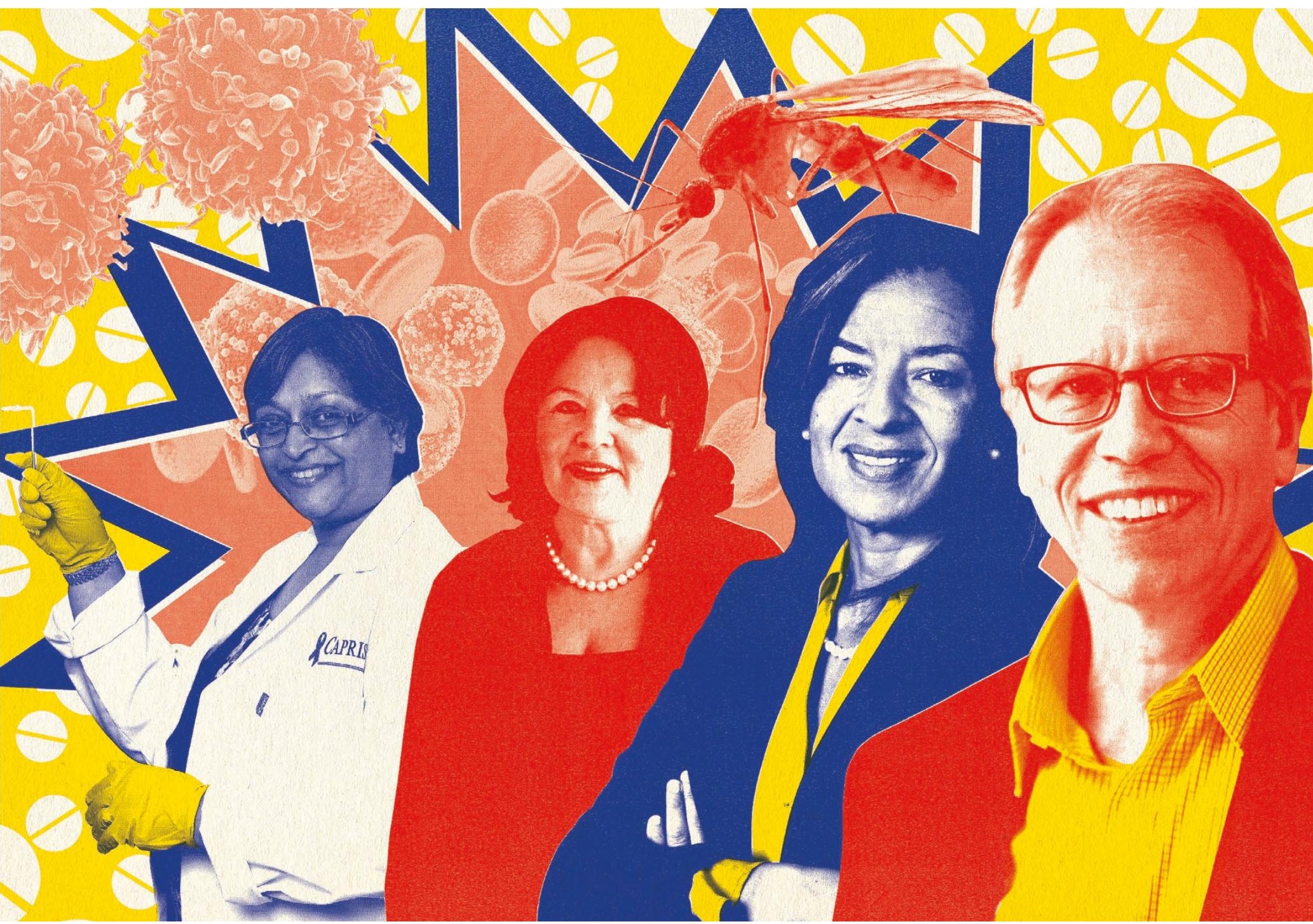

\title{
Patience for patients
}

\section{Researchers find that perseverance and an altruistic streak keep them going along the long road to drug discovery.}

\author{
BY NEIL SAVAGE
}

V hen Ripley Ballou - Rip to his friends - started to feel sick at a party in 1987, he thought it was because of his friend's home-brewed beer.

Ballou was taking a break from his work on developing a malaria vaccine at the Walter Reed Army Institute of Research in Silver Spring, Maryland, which he was doing in collaboration with the pharmaceutical giant GlaxoSmithKline (GSK). Back then, researchers could be a principal investigator as well as volunteer in their own projects. "We had a great tradition at Walter Reed where it was normal if you were developing a vaccine you had to take it yourself and you got your friends to take it with you," Ballou says. "So you'd walk down the hall and you'd get pulled in and they'd say, 'Would you be in my vaccine trial?' 'Sure, if you'll be in mine.'

$\mathrm{He}$ and his colleagues injected themselves with a candidate, then allowed themselves to be bitten by infected mosquitoes. If the vaccine worked, it would mean they were well on their way to conquering a disease that may have killed half of all the people who have ever lived.

He realized he was wrong about the beer when he got home from the party. He developed a fever of $39^{\circ} \mathrm{C}$ and the worst headache of his life. He had shaking chills, followed by a soaking sweat, in a cycle that was repeated half a dozen times over 48 hours. The experience had a profound impact. "I had no appreciation of what Left to right: Quarraisha Abdool Karim, Una Ryan, Bahija Jallal, Ripley Ballou. malaria was until I had it," Ballou says. "You're working on it, you read about it, you see people with it, but having it yourself was another experience and it made me want to beat that disease."

Seeing people endure malaria during field trials of vaccine candidates in southeast Asia and sub-Saharan Africa, where the disease is endemic, drove the point home. $\mathrm{He}$ 


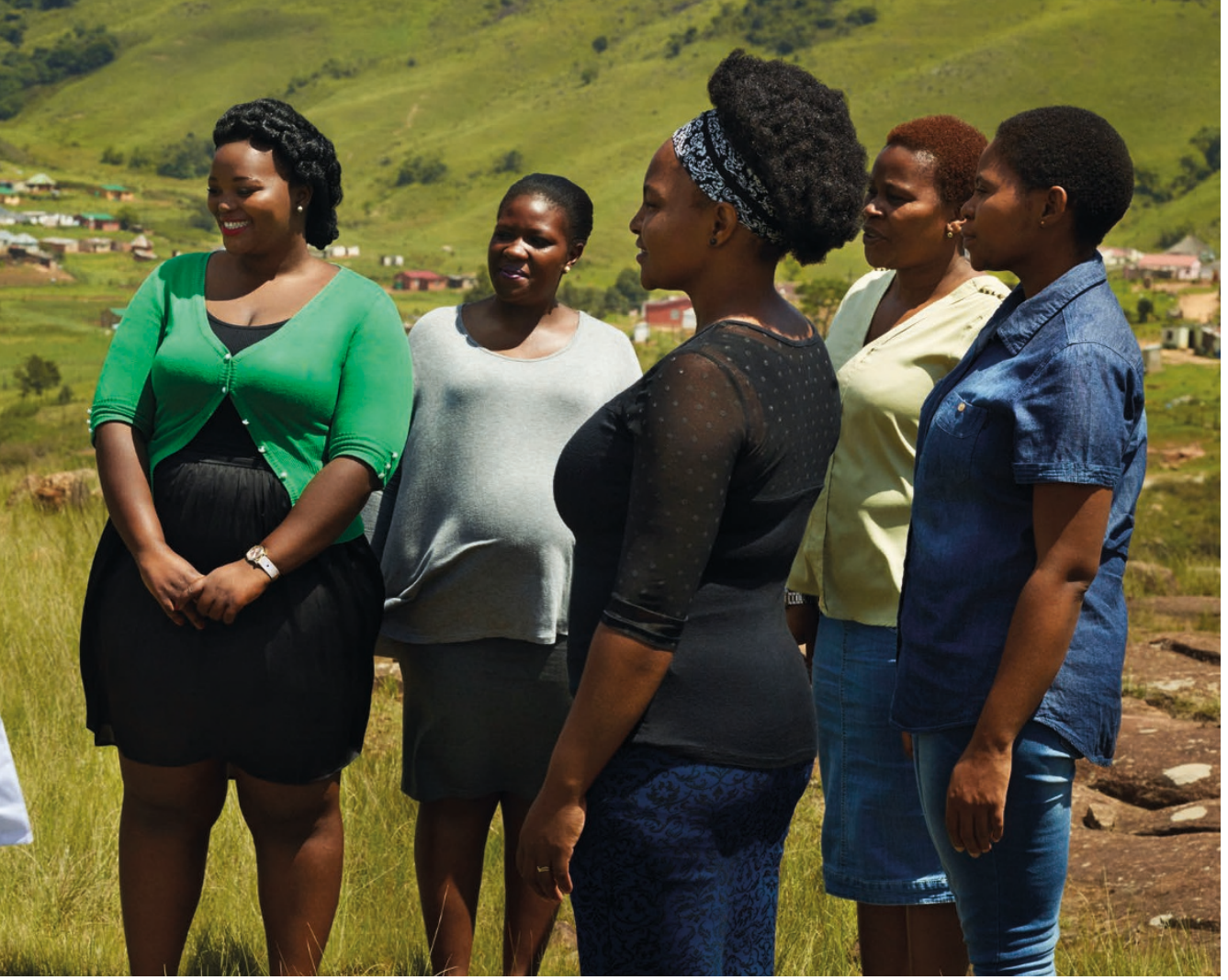

oral vaccine against rotavirus in infants, which she estimates saves about 400,000 lives a year. She does not want to measure her success with hard numbers, though. "I did not want to have on my gravestone, 'She saved X million lives' with a sort of tally of things," Ryan says. "I wanted to leave behind something that people wouldn't have had if I hadn't been here."

\section{THE DIFFERENCE BETWEEN LIFE AND DEATH}

Mark O'Connor knows the ups and downs that drug development can take. He joined a biotech start-up - KuDOS Pharmaceuticals in Cambridge, UK - in 1999 to work on the DNA damage response. A number of biological pathways check for and correct errors as cells replicate, but some of them are disabled in cancer cells. Steve Jackson, a molecular biologist at the University of Cambridge and founder of KuDOS, thought that if an inhibitor could be discovered to block the ones that persist in tumour cells, it would make an efficient cancerspecific therapy.

The team eventually identified olaparib. The drug showed promise in cancers with mutations in $B R C A 1$ and $B R C A 2$ - two genes that are normally involved in repairing DNA damage and, when mutated, are linked to some breast and other tumours. As with most small companies, there were struggles with money. O'Connor remembers the uncertainty when early funding was running out and new sources had not been secured, but he learned to set that worry aside. "If you spend all your time worrying about things you can't control then that's not good for you, so we just focused on delivering the science," he says.

By 2005, the company had made enough progress to be acquired by AstraZeneca, which helped to ramp up the research. But progress stalled. It had decided to test olaparib on a broader sample of ovarian cancers, not just those with $B R C A$ mutations. The results seemed promising, but regulatory agencies wanted more data on long-term survival, and in 2011, the company decided not to go into phase III trials.

Rather than give up, the researchers refocused their efforts on just the cancers with $B R C A$ mutations. They collected enough data that in 2012 they convinced the new AstraZeneca chief executive, Pascal Soriot, to move to phase III testing. Olaparib was ultimately approved in 2014 by both the US Food and Drug Administration and the European Medicines Agency.

Not long ago, O'Connor, now a chief scientist at AstraZeneca, was reminded of the real impact of the drug's success. A patient who had been taking olaparib wanted to meet the scientists who developed it. The 5-year survival rate for people with end-stage ovarian cancer is just $17 \%$, but this woman had responded well to chemotherapy and had been taking olaparib for more than six years to stop the tumour from growing again. She told O'Connor and his colleagues that the treatment had kept her alive to see two new grandchildren.

"It was just brilliant," O'Connor says. "She just was really thankful, and she encouraged myself and other people who had been working on this 'you just need to keep going', because it had made such a difference to their lives."

He finds such experiences to be a good motivator. "It just reinforces why we do what we do," he says. "And if you've had a bad day and you've had meetings that you are unhappy about or experiments haven't worked the way you thought they would, you just have to keep focused on the patient."

Neil Savage is a freelance writer based in Lowell, Massachusetts. 